\title{
Kajian Kelayakan Potensi Energi Angin Untuk Dimanfaatkan Menjadi Energi Listrik Disekitaran Legok - Kota Jambi
}

\author{
Leily. W. Johar \\ Jurusan Teknik Listrik, Fakultas Teknik, Universitas Batanghari \\ *Corresponding author, e-mail: leily_johar@yahoo.com
}

\begin{abstract}
Abstrak
Energi listrik adalah salah satu kebutuhan yang tidak dapat terlepas dari kehidupan manusia pada umumnya. Permintaanya akan energi listrik dari waktu ke waktu semakin meningkat, untuk itu sumber energi terbarukan yang tak terbatas ketersediaannya di alam perlu dikembangkan untuk memenuhi kebutuhan energi listrik. Di kota Jambi dan sekitarnya, Keadaan wilayah diliputi seputaran aliran sungai batanghari dan kondisi lapangan yang luas, bebas dari penghalang angin baik pohon- pohon dan gedunggedung untuk itu pada kondisi ini dipersyaratkan dapat dilakukan kajian - kajian penelitian lebih mendalam pembangkit listrik tenaga angin, dengan menggunakan data kecepatan angin pada suatu ketinggian tertentu memungkinkan didapatkannya ketersediaannya energi listrik. Pada Penelitian ini lokasi untuk mengetahui parameter energi angin adalah di kota Jambi dengan posisi geografis pada koordinat 1.59,103.600219, penelitian ini menggunakan metode survey eksploratif dengan melakukan pengukuran langsung di lapangan, penelitian ini bertujuan mengetahui potensi energi angin yang dapat dikonversikan menjadi energi listrik, seberapa layak kondisi kecepatan angin di kawasan kota Jambi untuk dimanfaatkan menjadi energi listrik. Dari data yang didapat Kecepatan angin rata-rata dalam setahun menggunakan data primer pada ketinggian 2 meter dari pinggiran sungai batanghari adalah sebesar 2,45 m/s dan besar daya efektif maksimum yang dihasilkan kincir angin dengan asumsi luas penampang $4 \mathrm{~m}^{2}$ adalah 374,68 Watt yang terjadi pada bulan juli, bila diaplikasikan pada spesifikasi Micro Wind Turbine Z - 400W[5] dapat menghasilkan energi listrik, namun kapasitas energi listrik yang dihasilkan sangat kecil.
\end{abstract}

Kata Kunci :

\begin{abstract}
Electrical energy is one of the needs that can not be separated from human life in general. The demand for electrical energy over time is increasing, for which an unlimited source of renewable energy availability in nature needs to be developed to meet the needs of electrical energy. In the city of Jambi and its surroundings, the state of the territory is covered by a stream of batanghari river flow and extensive field conditions, free from the wind barriers both the trees and buildings for which this condition is required to undertake more in-depth research studies of wind power, using wind speed data at a certain height allows for the availability of electrical energy. In this study the location to determine the parameters of wind energy is in the city of Jambi with geographic position at coordinates 1.59,103,600-219, this study uses explorative survey method by conducting direct measurement in the field, this study aims to determine the potential of wind energy that can be converted into electrical energy, how decent wind speed conditions in the city of Jambi to be utilized into electrical energy. From the data obtained, the average wind speed in a year using primary data at 2 meters from the batanghari river edge is $2.45 \mathrm{~m} / \mathrm{s}$ and the maximum effective power produced by the windmill assuming the $4 \mathrm{~m} 2$ cross-sectional area is 374.68 Watt which occurs in July, when applied to the Micro Wind Turbine Z $400 \mathrm{~W}$ [5] specification can generate electrical energy, but the resulting electrical energy capacity is very small.
\end{abstract}

Keywords : DRV 11873, Speed (RPM), PWM duty cycle

\section{PENDAHULUAN}

Krisis energi listrik global disebabkan oleh peningkatan bertahap pada populasi dunia sudah tidak dapat dihindari lagi, untuk itu kebutuhan untuk produksi energi listrik telah menghasilkan banyak minat pada sumber energi terbarukan. Energi angin merupakan salah satu sumber energi terbarukan dan masih sedikit pemanfaatannya di Indonesia. Pemanfaatan 
energi angin sebagai sumber energi terbarukan adalah suatu usaha menjawab masalah atas terjadinya perubahan lingkungan dan alam juga salah satu usaha konservasi dari sumber energi konvensional. Sebagai contoh, berdasarkan laporan $A W E A$ di Amerika untuk pembangkit daya angin $750 \mathrm{KW}$ dengan kecepatan angin $5.76 \mathrm{~m} / \mathrm{s}$ ketinggian $10 \mathrm{~m}$ yang beroperasi selama setahun mampu mengurangi emisi gasgas berbahaya antara lain 1179 ton $\mathrm{CO} 2 ; 6,9$ ton $\mathrm{SO} 2$ dan 4,3 ton $\mathrm{NO} 2$ atas penggunaan BBM.[1]. Indonesia sebagai negara yang berada di ekuator, potensi dari PLTB memang tidak terlalu besar. Beberapa daerah di Indonesia, misal NTB dan NTT, yang mempunyai potensi bagus. Sebagian besar daerah di Indonesia mempunyai kecepatan angin rata-rata sekitar 4 $\mathrm{m} / \mathrm{s}$, kecuali dua propinsi tersebut. PLTB cocok dikembangkan di Indonesia adalah pembangkit dengan kapasitas dibawah $100 \mathrm{KW}$ [2].

Kebutuhan akan energi, khususnya energi listrik di Indonesia makin berkembang menjadi bagian tak terpisahkan dari kebutuhan hidup masyarakat sehari-hari, maka diperlukan sebuah sumber energi baru yang mampu memenuhi kebutuhan listrik yang semakin besar. Untuk itu perlu adanya sumber energi alternatif yang berpotensi membangkitkan listrik dengan proses yang ramah lingkungan. Untuk mengatasi pemenuhan kebutuhan listrik, Angin sebagai sumber yang tersedia di alam dapat dimanfaatkan sebagai salah satu sumber energi listrik. Angin merupakan sumber energi yang tak ada habisnya sehingga pemanfaatan sistem konversi energi angin akan berdampak positif terhadap lingkungan.

Pemilihan kota jambi dikarenakan pusat dari pemerintahan provinsi Jambi selain itu kota jambi juga terletak di pinggiran aliran sungai batanghari, dimana masyarakat yang bertempat tinggal pada pinggiran sungai banyak menggantungkan hidupnya dengan berwirausaha keramba ikan, potensi dampak negatif akibat krisis energi sangat mengganggu aktifitas diberbagai bidang sehingga berdampak buruk pada perekonomian hasil yang diharapkan.

Keadaan wilayah yang diliputi seputaran aliran sungai batanghari dan kondisi lapangan yang luas, bebas dari penghalang angin baik pohon- pohon dan gedung-gedung untuk itu pada kondisi ini dipersyaratkan dapat dilakukan kajian - kajian penelitian lebih mendalam dengan menggunakan data kecepatan angin pada suatu ketinggian tertentu yang memungkinkan didapatnya data kecepatan angin yang lebih tinggi serta menggunakan turbin dengan spesifikasi yang merujuk pada keadaan angin di sekitar objek yang berpotensi angin. gambar 1 dibawah menunjukan kondisi daerah penelitian yang bertempat di legok , telanaipura kota jambi dengan koordinat $1.59,103.600219$.

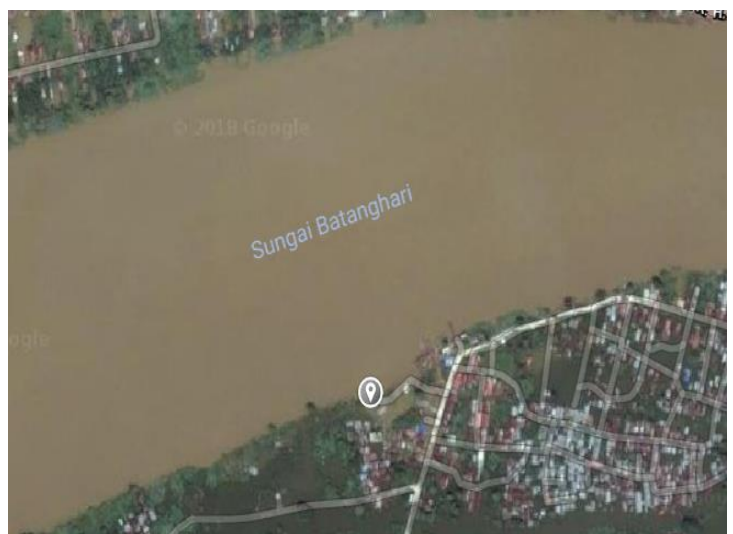

Gambar 1. lokasi penelitian

Pada penelitian ini dilakukan kajian tentang potensi angin pada daerah pinggiran sungai batanghari dimana pada penelitian ini dilakukan pengukuran lapangan tentang keadaan kecepatan angin dan direncanakan perancangan PLTB dengan spesifikasi yang cocok untuk kondisi angin yang ada, sehingga akan menghasilkan energi listrik yang lebih optimal. Untuk mengatasi masalah penggunaan PLTB yang ketersediaannya rendah juga dapat dioperasikan secara paralel dengan pembangkit listrik lainnya, pembangkit listrik lainnya bisa berbasis SEA atau pembangkit konvensional.

\section{TINJAUAN PUSTAKA}

Angin terjadi karena adanya perbedaan suhu antara udara panas dan udara dingin yang menyebabkan terjadinya suatu perputaran udara berupa perpindahan udara. Di daerah khatulistiwa, udaranya menjadi panas mengembang dan menjadi ringan, naik keatas dan bergerak ke daerah yang lebih dingin. sebaliknya daerah kutub yang dingin, udaranya menjadi dingin dan turun ke bawah. Sehingga terjadilah suatu perputaran udara berupa perpindahan udara dari kutub utara ke garis khatulistiwa menyusuri permukaan bumi dan 
sebaliknya suatu perpindahan udara dari garis katulistiwa kembali ke kutub utara, melalui lapisan udara yang lebih tinggi.[6]

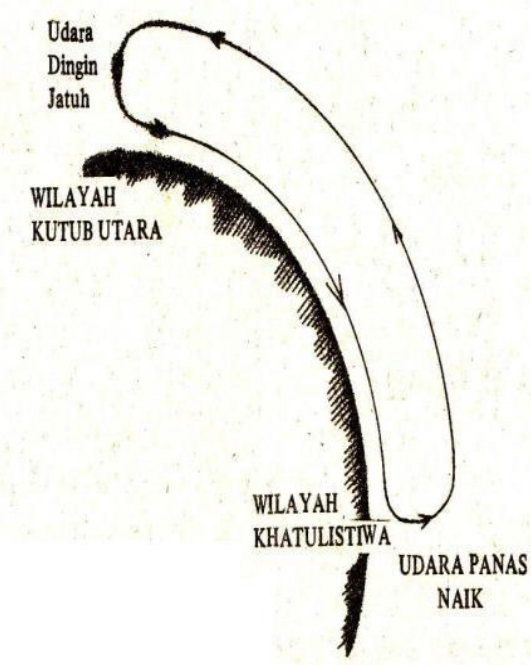

Gambar 2. Skema terjadinya angin[1]

Sebagaimana diketahui menurut fisika klasik energi kinetik dari sebuah benda dengan massa (m) dan kecepatan (v) adalah :

$$
\mathrm{E}=0,5 \mathrm{~m} \cdot \mathrm{v}^{2}
$$

dengan ketentuan, kecepatan (v) tidak mendekati kecepatan cahaya. Rumus itu berlaku juga untuk angin, yang merupakan udara yang bergerak.

Untuk keperluan praktis sering dipakai rumus pendekatan berikut:

$$
\begin{aligned}
& \mathbf{P}=\mathrm{k} \cdot \mathbf{A} \cdot \mathbf{v}^{\mathbf{3}} \\
& \text { dimana : } \\
& \mathrm{P}=\text { daya }(\mathrm{kW}) \text {; } \\
& \mathrm{k}=\text { suatu konstanta }\left(1,37.10^{-5}\right) \text {; } \\
& \mathrm{A}=\text { luas sudu kipas }\left(\mathrm{m}^{2}\right) \text {; } \\
& \mathrm{v}=\text { kecepatan angin }(\mathrm{km} / \mathrm{jam}) \text {. }
\end{aligned}
$$

pada persamaan (2) besaran $\mathrm{k}$ dan $\mathrm{A}$ sebagai konstanta, pada prinsipnya besaran $\mathrm{k}$ mewakili suatu faktor seperti geseran dan efesiensi sistem yang juga bergantung pada kecepatan angin (v), luas penampangsudu (A) bergantung dari bentuk sudu yang dapat diprediksi. Untuk mendapatkan daya efektif dari angin yang mungkin dihasilkan dari suatu kincir angin adalah:

$$
\mathrm{Ea}=\text { 0,5.C.p.A. } \mathrm{v}^{3}
$$

dimana :

$\mathrm{Ea}=$ Daya efektif yang dihasilkan kincir angin (watt)

$\mathrm{C}=$ Konstanta Bets yaitu konstanta harganya 16/27 (59,3\%) - batas Betz

$\mathrm{A}=$ Luas sapuan Rotor (dianggap $1 \mathrm{~m}^{2}$ )

$\mathrm{v}=$ Kecepatan angin $(\mathrm{m} / \mathrm{dt})$

$\rho=$ Kerapatan Udara diformulasikan sebagai berikut :

$\rho=\mathbf{P} /(\mathbf{R} . \mathbf{T})$

dimana :

$\rho=$ kerapatan udara $\left(\mathrm{kg} / \mathrm{m}^{3}\right)$

$\mathrm{P}=$ tekanan udara (pascal)

$\mathrm{R}=$ Konstanta gas $287,05 \mathrm{~J} / \mathrm{Kg} \cdot \mathrm{K}$

$\mathrm{T}=$ Temperatur (Kelvin)

selanjutnya konversi energi angin menjadi energi listrik dapat menggunakan formula :

$$
\left(P_{\text {syst }} / A\right)=0,1454 . v^{3}\left(w a t t / m^{2}\right)
$$

Selain dari data yang ditunjukan gambar sebelumnya, penentuan kecepatan angin suatu daerah dapat juga dilakukan dengan menggunakan metode probalistik distribusi Weibull dalam mengolah kumpulan data hasil survey seperti yang diperlihatkan pada gambar 3 dibawah.

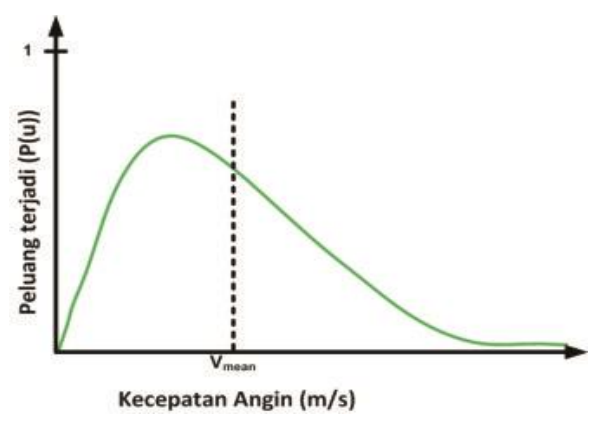

Gambar 3. Karakteristik Angin[4]

Karakteristik angin pada kondisi tertentu harus dapat dilakukan pengukuran secara berkala untuk didapat kecepatan rata - rata angin, sehingga daya mekanik dari turbin angin seperti ditunjukan gambar 4 dibawah dapat dioptimalkan. 


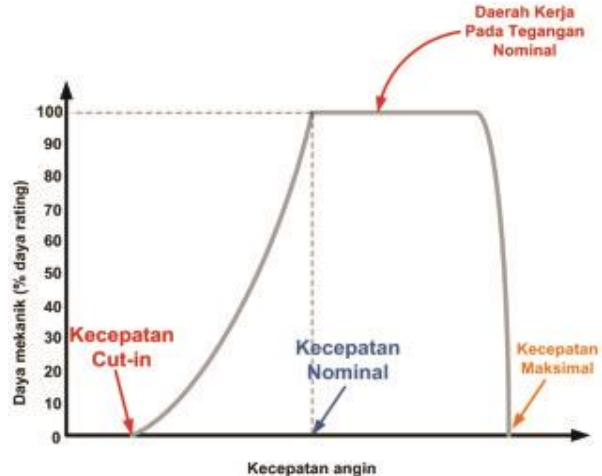

Gambar 4. Karakteristik Kerja Daya Mekanik Turbin Angin[4]

Angin dapat bergerak secara horizontal maupun vertikal dengan kecepatan yang dinamis dan fluktuatif. Pergerakan angin secara horizontal dinamakan adveksi, sedangkan pergerakan secara vertikal dinamakan konveksi. Dalam pemanfaatan energi angin diperlukan data atau informasi mengenai potensi energi angin aktual yang tersedia di lokasi pemasangan dan pemanfaatan sesuai kebutuhan di lokasi tersebut.

\section{METODOLOGI}

Pada Penelitian ini lokasi untuk mengetahui parameter energi angin adalah di kota Jambi dengan posisi geografis pada koordinat 1.59,103.600219.

Penelitian ini menggunakan metode survey eksploratif dengan melakukan pengukuran langsung di lapangan, berdasarkan penelitian ini yaitu mengetahui potensi energi angin yang dapat dikonversikan menjadi energi listrik, seberapa layak kondisi kecepatan angin di kawasan kota Jambi untuk dimanfaatkan menjadi energi listrik, dengan mengolah data kecepatan angin rata-rata, sehingga dapat diketahui seberapa layak potensi energi angin di kawasan kota Jambi khususnya legok untuk dikonversikan menjadi energi listrik yang dihasilkan selama setahun dengan acuan potensi angin berdasarkan kecepatan angin di lokasi penelitian. Gambar 5 dibawah menjelaskan flowchart dari penelitian.

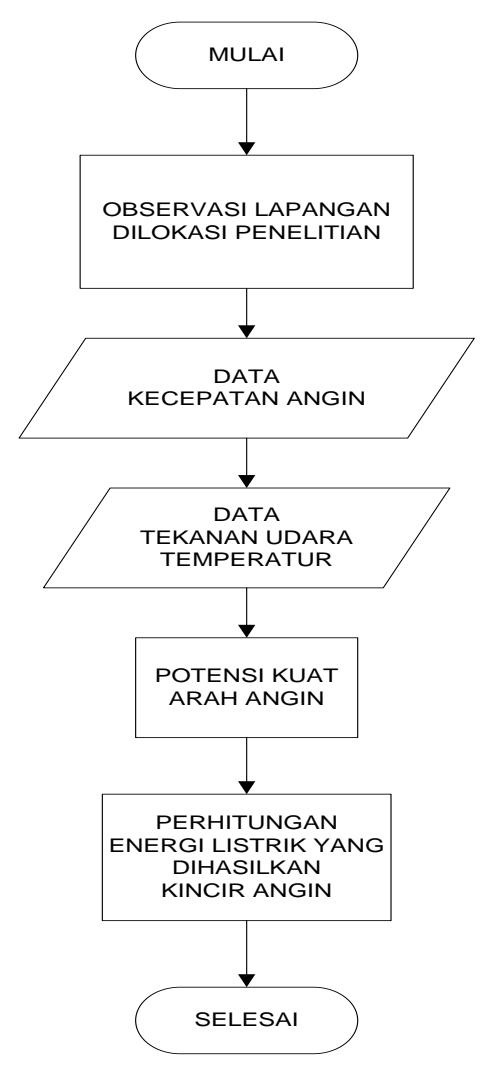

Gambar 5.flowchart penelitian

\section{HASIL ANALISA PERCOBAAN 4.1. Kecepatan Rata-Rata Tiap Bulan Dalam Setahun}

Untuk mendapatkan kecepatan angin di lokasi penelitian dilakukan pengukuran tiap bulan menggunakan alat ukur wind speed dg81, dengan ketinggian 2 meter dari pinggiran area sungai batanghari. Dari data hasil pengukuran kecepatan angin tiap bulan dalam setahun dapat dilihat dari tabel. 1. dibawah.

Tabel 1. Data kecepatan angin rata-rata setahun

\begin{tabular}{llcl}
\hline \multicolumn{4}{c}{ DATA KECEPATAN ANGIN } \\
NO & Bulan & $\begin{array}{r}\text { Kecepatan } \\
(\mathrm{m} / \mathrm{s})\end{array}$ & \multicolumn{1}{c}{ Arah } \\
\hline 1 & Jan & 1,4 & Timur \\
2 & Feb & 1,4 & Barat \\
3 & Mar & 4,6 & Barat Laut \\
4 & Apr & 1,5 & Barat \\
5 & Mei & 2,6 & Tenggara
\end{tabular}




\begin{tabular}{llll}
6 & Jun & 2,6 & Barat Daya \\
7 & Jul & 6,5 & Selatan \\
8 & Agust & 0,7 & Barat \\
9 & Sept & 1,6 & Barat \\
10 & Okt & 2,7 & Tenggara \\
11 & Nov & 2,2 & Barat \\
12 & Des & 1,7 & Barat \\
\hline
\end{tabular}

Dari Tabel diatas, distribusi angin baik arah maupun kecepatan dapat dihitung dengan menggunakan software WRPLOT View berbasis Windows yang memunculkan perhitungan wind rose dengan tampilan grafis yang menggambarkan variable meteorologi untuk rentang waktu dan tanggal sesuai kebutuhan pengguna. Wind rose menggambarkan frekuensi kejadian angin pada tiap arah mata angin dan kelas kecepatan angin pada lokasi dan waktu tertentu, perhitungan wind rose tidak selalu mewakili pergerakan riil angin di wilayah tersebut. Grafik frekuensi distribusi arah dan kecepatan angin dibuat dengan menggunakan software WRPLOT View seperti gambar 6. dibawah

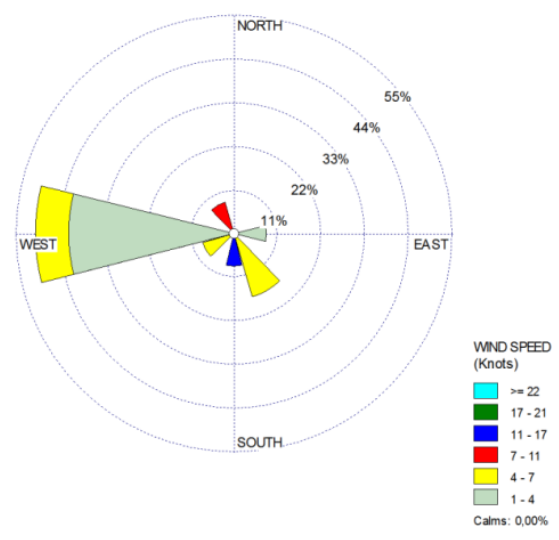

Gambar 6. Data Angin Manggunakan Software WRPlot

Wind rose dapat pula digunakan untuk menampilkan grafik dari kecenderungan arah pergerakan angin pada suatu wilayah. frekuensi distribusi dari data lapangan seperti ditunjukan gambar 7 dibawah.

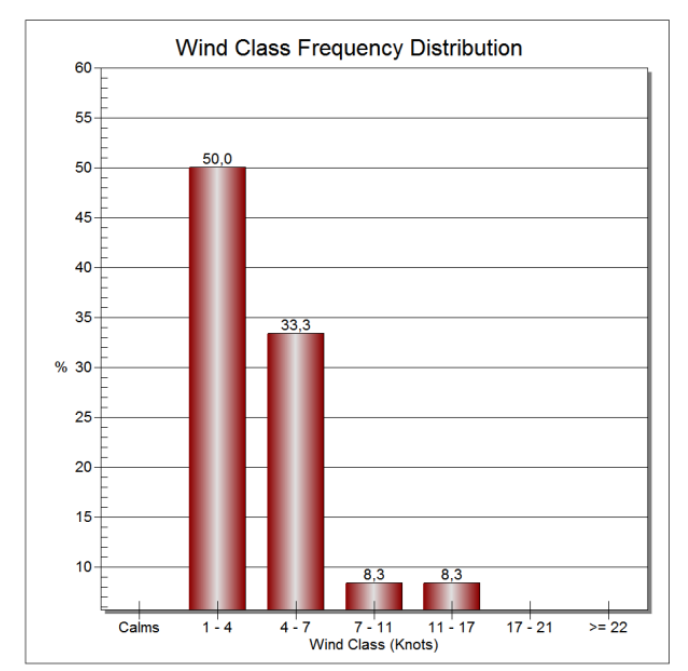

Gambar 7. Grafik Data Angin Manggunakan Software WRPlot

\subsection{Perhitungan Daya Efektif yang dihasilkan Kincir Angin}

Untuk mencari Daya efektif (Ea) yang diambil turbin angin yang terletak dalam aliran angin dapat ditentukan dengan menggunakan persamaan (3). Parameter - parameter dalam melakukan perhitungan daya efektif adalah dengan mendapatkan besaran dari data temperatur dan tekanan udara di lokasi penelitian, adapun besar tekanan dan temperatur rata- rata setiap bulannya selama setahun diperlihatkan pada tabel 2 dibawah.

Tabel 2. Tekanan dan Temperatur setiap bulan selama setahun

\begin{tabular}{llc}
\hline BULAN & ARAH & $\begin{array}{c}\text { DAYA EFEKTIF } \\
\text { (watt) YANG } \\
\text { DIHASILKAN } \\
\text { KINCIR ANGIN } \\
\text { (Ea) }\end{array}$ \\
\hline JAN & Timur & 3,711214052 \\
FEB & Barat & 3,783337796 \\
MARET & barat laut & 130,9973517 \\
APRIL & Barat & 4,633505112 \\
MEI & tenggara & 23,81324083
\end{tabular}




\begin{tabular}{llc} 
& barat & \\
JUNI & daya & 23,99569851 \\
JULI & selatan & 374,6844819 \\
AGUSTUS & Barat & 0,47027805 \\
SEPTEMBER & Barat & 5,610375849 \\
OKTOBER & tenggara & 26,84474805 \\
NOVEMBER & Barat & 14,49392623 \\
DESEMBER & Barat & 6,762789101 \\
\hline
\end{tabular}

Adapun besar daya efektif setiap bulannya berdasarkan arah angin diperlihatkan pada tabel 3. dibawah dimana besar penampang kincir angin diasumsikan $4 \mathrm{~m}^{2}$.

Tabel 3. Hasil perhitungan Daya Efektif yang dihasilkan kincir angin selama setahun

\begin{tabular}{llc}
\hline \multicolumn{1}{c}{ BULAN } & $\begin{array}{c}\text { DAYA } \\
\text { EFEKTIF (watt) } \\
\text { YANG }\end{array}$ & $\begin{array}{c}\text { YANG } \\
\text { DIHASILKAN } \\
\text { KINCIR } \\
\text { ANGIN (Ea) }\end{array}$ \\
\hline JANUARI & Timur & 3,711214052 \\
FEBRUARI & Barat & 3,783337796 \\
MARET & barat laut & 130,9973517 \\
APRIL & Barat & 4,633505112 \\
MEI & tenggara & 23,81324083 \\
JUNI & barat daya & 23,99569851 \\
JULI & Selatan & 374,6844819 \\
AGUSTUS & Barat & 0,47027805 \\
SEPTEMBER & Barat & 5,610375849 \\
OKTOBER & tenggara & 26,84474805 \\
NOVEMBER & Barat & 14,49392623 \\
DESEMBER & Barat & 6,762789101 \\
\hline
\end{tabular}

Dari tabel 3 diatas dapat dijelaskan besar energi listrik yang dihasilkan selama setahun terjadi pada bulan juli yaitu sebesar 374, 684 watt dengan kuat arah angin menuju selatan. Gambar 8 dibawah menjelaskan rata-rata besar daya efektif yang dihasilkan selama setahun.

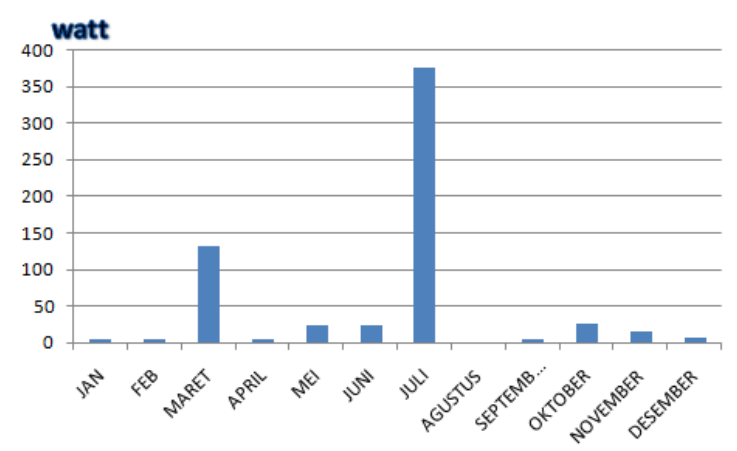

Gambar 8. Rata-rata Besar Daya Efektif yang Dihasilkan Selama Setahun

\section{SIMPULAN}

Berdasarkan analisa dari hasil survey eksploratif dan perhitungan data primer kecepatan angin dilapangan dapat diambil beberapa kesimpulan sebagai berikut :

1. Kecepatan angin rata-rata dalam setahun menggunakan data primer pada ketinggian diatas 2 meter adalah sebesar $2,45 \mathrm{~m} / \mathrm{s}$ dimana kecepatan angin tersebut masuk dalam kategori angin kelas 3 (tiga) yang masih dapat dimanfaatkan potensinya.

2. Dari data kecepatan angin selama setahun daya efektif yang dihasilkan kincir angin dengan asumsi luas penampang $4 \mathrm{~m}^{2}$, besar daya efektif maksimum adalah 374,68 Watt yang terjadi pada bulan juli

3. Dari data kecepatan angin yang diperoleh selama setahun bila diaplikasikan pada spesifikasi Micro Wind Turbine $\mathrm{Z}$ 400W[5], dapat menghasilkan energi listrik, namun kapasitas energi listrik yang dihasilkan kecil, maka konversi energi angin menjadi energi listrik tersebut masuk di dalam kelompok I standar angin Indonesia, sehingga potensi anginnya kurang baik untuk didaya gunakan.

\section{DAFTAR PUSTAKA}

[1] Abdul Kadir, Energi Sumber Daya, Inovasi, Tenaga Listrik Dan Potensi Ekonomi, Edisi Ke dua tahun 1995,Penerbit Universitas Indonesia, Jakarta. 
JEPCA: Journal of Electrical Power Control and Automation Vol.1 No.1 Juni 2018 e-ISSN 2621-556X

[2] Douglas C.Giancoli, Physics For Scientists And Enginers, Second Edition 1988

[3]Pembangkit Listrik Tenaga Angin. http://www.kincirangin.info, (diakses 10 Mei 2013, pukul 10:24 WIB)

[4] Kadek fendy sutrisno, (2011), prinsip kerja pembangkit listrik tenaga angin dan perkembangannya di dunia, https://indone5ia.wordpress.com (diakses 21 Mei 2017, pukul 1:30 WIB).

[5] Indotrading, wind power 400 watt Horizontal-Pembangkit Listrik Tenaga Angin,tersedia:https://www.indotrading. com, (diakses 06 januari 2017, pukul 10:00 WIB)

[6]Y.Daryanto,. Kajian Potensi Angin Untuk Pembangkit Listrik Tenaga Bayu, Yogyakarta, Balai PPTAGG. 